\title{
The Prognostic Values Of Circulating Tumor Cells In Lung Carcinoma: An Analysis On 98 Chinese Patients
}

This article was published in the following Dove Press journal: OncoTargets and Therapy

\author{
Min-Hua Tan',* \\ Zhi-Geng Zhong ${ }^{2, *}$ \\ Pan-Long Chen ${ }^{3, *}$ \\ Yi-Xing Zhou ${ }^{3}$
}

'Department of Pathology, First People's Hospital of Zhaoqing City, Zhaoqing City, Guangdong Province, People's Republic of China; ${ }^{2}$ Department of Neurology, First People's Hospital of Zhaoqing City, Zhaoqing City, Guangdong Province, People's Republic of China; ${ }^{3}$ Department of Neurosurgery, First People's Hospital of Zhaoqing City, Zhaoqing City, Guangdong Province, People's Republic of China

*These authors contributed equally to this work
Correspondence: Yi-Xing Zhou

Department of Neurosurgery, First People's Hospital of Zhaoqing City, No. 9 Donggang East Road, Duanzhou District, Zhaoqing City, Guangdong Province 526060, People's Republic of China

Tel/fax +86-758-2102860

Email zqyybgs@I63.com

\begin{abstract}
Aim: To examine the prognostic values of circulating tumor cells (CTCs) in patients with advanced lung cancer.

Patients and methods: A total of 98 patients with their CTCs enumerated in 2017 was recruited. Data were retrieved from medical records for comparison. Patients' overall survival (OS) and progression-free survival (PFS) were studied using Kaplan-Meier curve with log rank test.

Results: Seventy-three percent of the patients were male, and nearly half of the patients (44.8\%) were smokers. Most tumors were adenocarcinoma (73.4\%), and about $60 \%$ of the cases were diagnosed at stage IV. Half of the patients showing less than nine CTCs. Patients' OS were significantly associated with total CTC count $(P=0.047)$, epithelial CTC count $(P=0.027)$, mixed CTC count $(P=0.004)$, and use of adjuvant chemotherapy $(P=0.001)$. For PFS, it was strongly associated with tumor backgrounds (T stage, $P=0.002 ; \mathrm{M}$ stage, $P=0.001$; TMN stage, $P<0.001$ ), cancer biomarkers (CEA, $P=0.004$; CA125, $P=0.004$; CA153, $P=0.045$ ), and treatment strategy (surgical intervention, $P=0.025$; first-line chemotherapy, $P<0.001)$.
\end{abstract}

Conclusion: The present study clearly indicated the significant associations between CTC and overall survival of patients with lung cancer.

Keywords: circulating tumor cells, survival, lung cancer, prognostic values

\section{Introduction}

Lung cancer is a deadly malignancy which affects populations worldwide, with the highest incidence rates among males in the United States and Eastern Europe, while the highest rates among females are in North America and Northern Europe. ${ }^{1}$ Cigarette smoking has long been identified, as is the major etiology of lung cancer. $^{2,3}$ Over the past decade, air pollution and certain occupational exposures have emerged as environmental factors that elevate the risk of developing lung cancer. ${ }^{4,5}$

Surgical resection is a potential curative approach for the treatment of early lung cancer; however, in most clinical scenarios, patients are not eligible to the surgical treatment because their cancers are diagnosed as advanced tumors at the first time of presentation. ${ }^{6}$ Cytotoxic chemotherapy and targeted therapies, eg, tyrosine kinase inhibitors (TKIs), have emerged as other treatment options for patients with advanced lung cancer; however, unfortunately, the reported response rates in such patients are not very satisfactory. ${ }^{7}$ 
A better understanding of the clinical factors affecting the prognosis of patients after treatment would provide invaluable insights into the refinement of management strategy for patients with advanced lung cancer. Biomarkers that are accurately prognostic of the disease progression are of clinical importance too. Recently, in addition to the widelyinvestigated protein and nucleic acid-based circulating biomarkers, circulating tumor cells (CTCs) have emerged as promising prognostic biomarkers for lung cancer. CTCs are epithelial cells that can only be specifically detected in patients with cancer but not in healthy subjects. CTCs are classified into three types according to their phenotypes: epithelial, CTCs with epithelial phenotype; mesenchymal, CTCs with mesenchymal phenotype; and mixed, CTCs with mixed epithelial-mesenchymal phenotype. Despite their low frequency in blood circulation, CTCs play roles in tumorigenesis and metastasis. ${ }^{8,9}$ Recent technologies have been developed for the accurate enumeration of CTCs in different cancers, with the prognostic significance of CTCs illustrated in multiple malignancies including breast, colorectal, and prostate cancer. ${ }^{10-12}$ The roles of CTCs in the diagnosis and disease monitoring in lung cancer have also been explored. ${ }^{13,14}$

Despite the important findings of CTCs in different cancers, the correlation of CTCs with patients' survival in Asian patients, especially Chinese, has yet to be fully established. Therefore, the present study was primarily aimed to examine if CTC count would be prognostic of Chinese patients' survival outcomes. This work also studied the associations between CTC and commonly used cancer biomarkers. Besides, the clinical parameters affecting the survival outcomes of patients were also studied. These results would collectively provide novel insights into the refinement of treatment strategy for patients with advanced lung cancer.

\section{Patients And Methods Study Population}

The present study was a retrospective study that retrieved and analyzed clinical data of 98 patients with lung carcinoma, who received treatments in 2017 in The First People's Hospital of Zhaoqing City (Zhaoqing, Guangdong, China). All cases were histologically confirmed as lung cancer. Individuals with non-malignant lung diseases and systemic disorders were not included. The study was approved by the Ethics Committee and Institutional Review Board of First People's Hospital of Zhaoqing City. All participants received written and oral information prior to giving written consent, and the study was performed in accordance with the Helsinki II declaration.

\section{RNA In Situ Hybridization In CTC}

CTCs were determined using RNA in situ hybridization. In brief, $5 \mathrm{~mL}$ of peripheral blood was collected from each patient with an EDTA tube at the time of admission, and was incubated with red blood cell lysis buffer $(154 \mathrm{mM}$ $\mathrm{NH}_{4} \mathrm{Cl}, 10 \mathrm{mM} \mathrm{KHCO} 3,0.1 \mathrm{mM}$ EDTA) at room temperature for 30 minutes. After centrifugation at $500 \mathrm{~g}$ for 5 minutes, the resulting cell pellet was resuspended in phosphate-buffered saline (PBS) and fixed with $4 \%$ formaldehyde for 8 minutes. Fixed cells were then transferred on a membrane with a pore size of $8 \mu \mathrm{m}$, which is shown to be able to retain CTCs.

CTCs fixed on the membrane were hybridized with RNA probes targeting epithelial markers (ie, EpCAM and CK8/18/19), mesenchymal markers (ie, vimentin and twist), and leukocyte marker $\mathrm{CD} 45$ at $40^{\circ} \mathrm{C}$ for 3 hours. After washing, the hybridized probes were detected by hybridizing with respective Alexa Fluor probes (ie, epithelial markers, Alexa Fluor 594; mesenchymal markers, Alexa Fluor 488; leukocyte marker, Alexa Fluor 750) at $40^{\circ} \mathrm{C}$ for 30 minutes. The resulting signal was captured using automatic fluorescent scanner.

\section{Clinical Data}

The clinical data included demographic data (ie, age and gender), tumor characteristics (ie, size, location, TNM stage, cancer markers), CTC data (ie, number, type, time of detection), treatment strategy (ie, chemotherapy, radiotherapy, molecular targeted therapy, surgery), and clinical outcomes (ie, progression-free survival [PFS] and overall survival [OS]).

\section{Statistical Analysis}

All analyses were performed using statistical software SAS version 9.3. Continuous variables with and without normal distribution were analyzed using Student's $t$-test and Wilcoxon two sample test, respectively. For comparisons between three or more groups, the normally-distributed data were analyzed using one-way analysis of variance, Kruskal-Wallis test was performed otherwise. StudentNewman Keuls (SNK) method, which is a stepwise multiple comparisons procedure, was employed to identify pairwise comparisons that were significantly different from each other. Comparisons between counting variables were done using chi-square or Fisher's exact test. Patients' OS and PFS 
were studied using Kaplan-Meier curves with log rank test, with the differences between survival curves evaluated using Tukey-Kramer corrected $P$-values. Statistical significance was indicated by $P<0.05$.

\section{Results}

\section{Baseline Characteristics Of Enrolled Patients}

A total of 98 patients with lung carcinoma were enrolled. Seventy-three percent of the patients were male, and nearly half of the patients (44.8\%) were smokers (Table 1). Most

Table I Baseline Characteristics Of Patients And Tumors

\begin{tabular}{|c|c|c|}
\hline \multicolumn{2}{|l|}{ Clinical parameters } & \multirow{2}{*}{$\begin{array}{l}\text { Number of } \\
\text { patients, } n \text { (\%) } \\
49(73.1) \\
18(26.9)\end{array}$} \\
\hline Gender $(n=67)$ & $\begin{array}{l}\text { Male } \\
\text { Female }\end{array}$ & \\
\hline Age, years $(n=67)$ & $\begin{array}{l}<60 \\
\geq 60\end{array}$ & $\begin{array}{l}29(43.3) \\
38(56.7)\end{array}$ \\
\hline Smoker $(n=67)$ & $\begin{array}{l}\text { No } \\
\text { Yes }\end{array}$ & $\begin{array}{l}37(55.2) \\
30(44.8)\end{array}$ \\
\hline $\begin{array}{l}\text { Maximum tumor diameter, } \\
\mathrm{cm}(\mathrm{n}=53)\end{array}$ & $\begin{array}{l}<3.5 \\
\geq 3.5\end{array}$ & $\begin{array}{l}26(49.1) \\
27(50.9)\end{array}$ \\
\hline Tumor site $(n=67)$ & $\begin{array}{l}\text { Right side } \\
\text { Left side }\end{array}$ & $\begin{array}{l}42(62.7) \\
25(37.3)\end{array}$ \\
\hline Pathological type $(n=64)$ & $\begin{array}{l}\text { Adenocarcinoma } \\
\text { Other }\end{array}$ & $\begin{array}{l}47(73.4) \\
17(26.6)\end{array}$ \\
\hline Differentiation $(n=48)$ & $\begin{array}{l}\text { Low } \\
\text { Moderate } \\
\text { High }\end{array}$ & $\begin{array}{l}15(31.6) \\
28(58.3) \\
5(10.4)\end{array}$ \\
\hline TNM stage $(n=64)$ & $\begin{array}{l}\text { I-II } \\
\text { III } \\
\text { IV }\end{array}$ & $\begin{array}{l}9(14.1) \\
18(28.1) \\
37(57.8)\end{array}$ \\
\hline CEA $(n=89)$ & $\begin{array}{l}<5 \\
\geq 5\end{array}$ & $\begin{array}{l}57(64.0) \\
32(36.0)\end{array}$ \\
\hline CYFRA2 $(n=23)$ & $\begin{array}{l}<10 \\
\geq 10\end{array}$ & $\begin{array}{l}21(91.3) \\
2(8.7)\end{array}$ \\
\hline CAI99 $(n=74)$ & $\begin{array}{l}<37 \\
\geq 37\end{array}$ & $\begin{array}{l}57(77.0) \\
17(23.0)\end{array}$ \\
\hline CAI25 $(n=88)$ & $\begin{array}{l}<35 \\
\geq 35\end{array}$ & $\begin{array}{l}52(59.1) \\
36(40.9)\end{array}$ \\
\hline CAI53 $(n=74)$ & $\begin{array}{l}<38.6 \\
\geq 38.6\end{array}$ & $\begin{array}{l}67(90.5) \\
7(9.5)\end{array}$ \\
\hline
\end{tabular}

of the tumors were classified as adenocarcinoma (73.4\%), and about $60 \%$ of the cases were diagnosed at stage IV (Table 2). The CTCs of patients were enumerated, with about half of the patients showing less than 9 CTCs (Table 2). The numbers of different CTCs were also counted. The average count of epithelial, mesenchymal, and mixed CTCs was 8.9, 4.19, and 3.03, respectively. For the treatments of the patients, $64 \%$ received surgical interventions, and portions of the patients were administered adjuvant therapy (8.2\%), first-line chemotherapy $(31.6 \%)$, radiotherapy $(13.3 \%)$, and molecular targeted therapy (34.7\%) (Table 3). The clinical outcomes of patients after treatments were also studied (Table 4). Within the first year after the commencement of treatment, disease progression was observed in $27.9 \%$ of the patients.

Table 2 Characteristics Of Circulating Tumor Cells Of The Enrolled Patients $(n=98)$

\begin{tabular}{|l|l|l|}
\hline \multicolumn{2}{|l|}{ Enumerated CTC } & $\begin{array}{l}\text { Number of } \\
\text { patients, } \mathbf{n}(\%)\end{array}$ \\
\hline Total cell count & Not detected & $10(10.2)$ \\
& $<9$ & $53(54.1)$ \\
& $\geq 9$ & $35(35.7)$ \\
\hline Cell count - epithelial & Not detected & $30(30.6)$ \\
& $<3$ & $38(38.8)$ \\
& $\geq 3$ & $30(30.6)$ \\
\hline Cell count - mesenchymal & Not detected & $47(47.9)$ \\
& $<2$ & $17(17.4)$ \\
& $\geq 2$ & $34(34.7)$ \\
\hline Cell count - mixed & Not detected & $26(26.5)$ \\
& $<6$ & $47(48.0)$ \\
& $\geq 6$ & $25(25.5)$ \\
\hline
\end{tabular}

Table 3 Cancer Treatment For The Enrolled Patients

\begin{tabular}{|l|l|l|}
\hline \multicolumn{2}{|l|}{ Treatment strategy } & Number of patients, n (\%) \\
\hline Surgery $(n=65)$ & No & $23(35.4)$ \\
& Yes & $42(64.6)$ \\
\hline Adjuvant therapy & No & $90(91.8)$ \\
& Yes & $8(8.2)$ \\
\hline First-line chemotherapy & No & $67(68.4)$ \\
& Yes & $31(31.6)$ \\
\hline Radiotherapy & No & $85(86.7)$ \\
& Yes & $13(13.3)$ \\
\hline Molecular targeted therapy & No & $64(65.3)$ \\
& Yes & $34(34.7)$ \\
\hline
\end{tabular}


Table 4 Clinical Outcome Of Patients After Treatment

\begin{tabular}{|l|l|l|}
\hline \multicolumn{2}{|l|}{ Clinical outcome after treatment } & $\begin{array}{l}\text { Number of } \\
\text { patients, } n \text { (\%) }\end{array}$ \\
\hline Progressive disease $(n=95)$ & $\begin{array}{l}\text { No } \\
\text { Yes }\end{array}$ & $\begin{array}{l}61(64.2) \\
34(35.8)\end{array}$ \\
\hline Progression within I year (n=86) & $\begin{array}{l}\text { No } \\
\text { Yes }\end{array}$ & $62(72.1)$ \\
& $24(27.9)$ \\
\hline Survival $(n=95)$ & Survived & $75(78.9)$ \\
& Died & $20(21.1)$ \\
\hline
\end{tabular}

\section{Correlation Of CTCs With Cancer Biomarkers}

We examined whether there would be any relationship between the number of CTCs and expression of cancer markers. To this end, we compared the level of cancer biomarkers between patients showing different CTC number. Our analysis clearly illustrated that between patients with different CTC counts, there were no significant differences in CEA $(P=0.396)$, CYFRA2 $(P=0.580)$, CA199 $(P=0.700)$, CA125 $(P=0.452)$, or CA153 $(P=0.792)$.
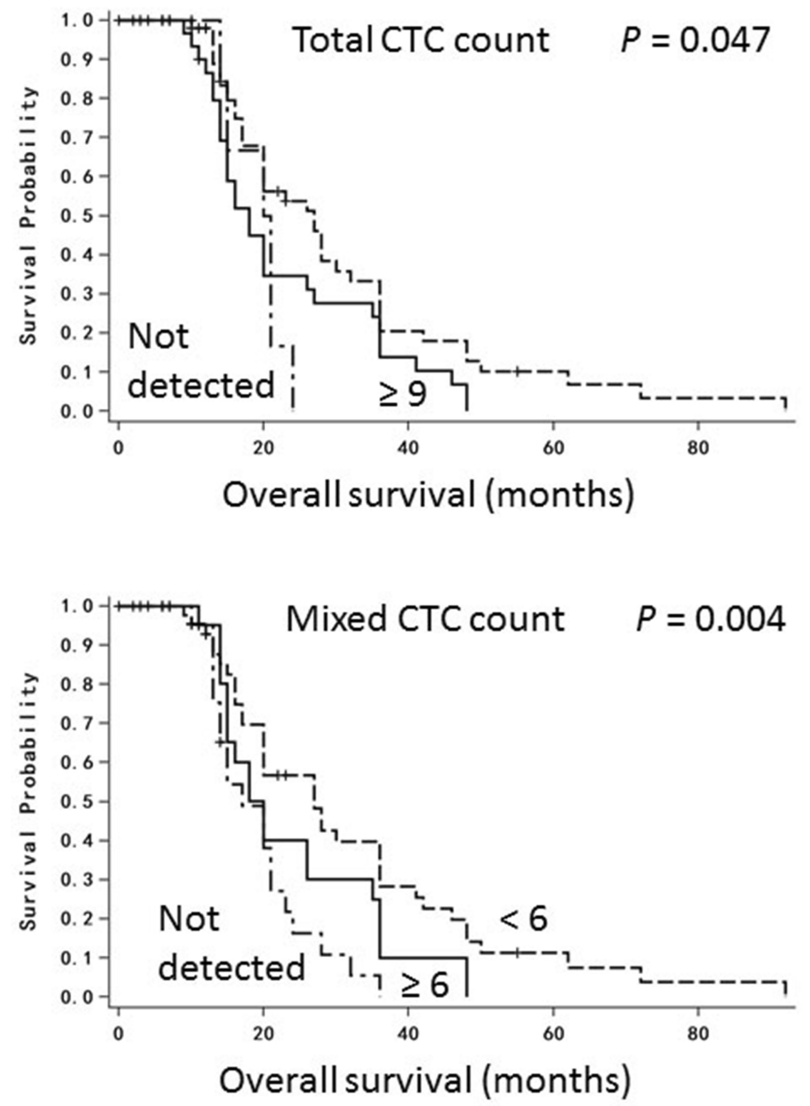

\section{Correlation Of CTCs With Patients' OS} And PFS

The overall survival of patients with different CTC counts were compared (Figure 1). Log-rank analysis clearly indicated the significant difference in OS between patients with different total CTC counts $(P=0.047)$, with patients whose total count was smaller than 9 , demonstrating the largest median survival of 27 months. There were also significant differences in OS between patients with different numbers of epithelial CTC $(P=0.027)$ and mixed-type CTC $(P=0.004)$. In addition to OS, the correlation of CTCs with patients' PFS was also examined, however no significant differences in PFS were seen between patients with different total $\mathrm{CTC}$ count $(P=0.413)$ and numbers of epithelial CTC $(P=0.542)$ and mixed-type CTC $(P=0.782)$.

\section{Association Between Clinical Parameters And Patients' Survivals}

The clinical parameters associated with patients' OS and PFS were also studied. By log-rank analysis, the use of adjuvant chemotherapy was shown to significantly affect

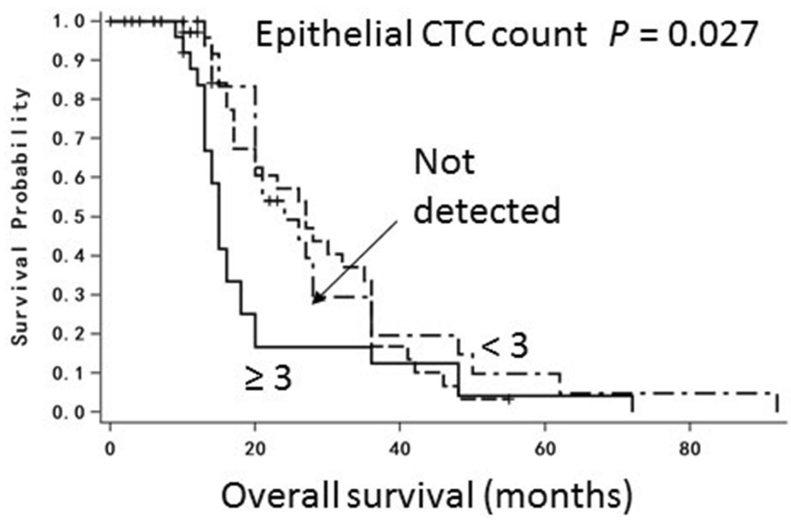

Figure I Kaplan-Meier curves showing the overall survivals of patients with different CTC counts (total count, epithelial CTC, and mixed-type CTC). P-value of the comparison was determined using log rank test. 
the OS of patients $(P=0.001)$ (Figure 2). Using the same way, multiple clinical parameters were identified as the clinical correlates of patients' PFS. Of the tumor background, patients' $\mathrm{PFS}$ was associated with $\mathrm{T}$ stage $(P=0.002)$, M stage $(P=0.001)$, and TMN stage $(P<0.001)$

(Figure 3). The PFS correlated also cancer biomarkers CEA

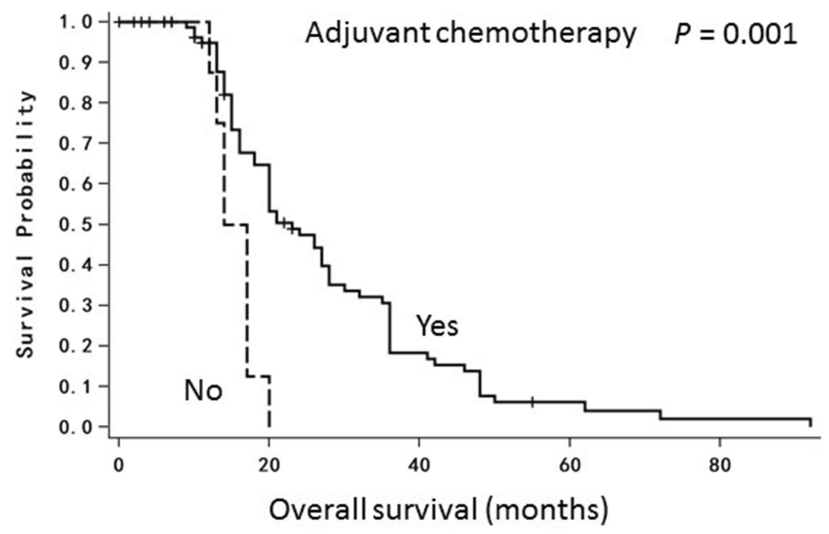

Figure 2 Kaplan-Meier curves showing the overall survivals of patients who had and had not received adjuvant chemotherapy. $P$-value of the comparison was determined using log rank test.
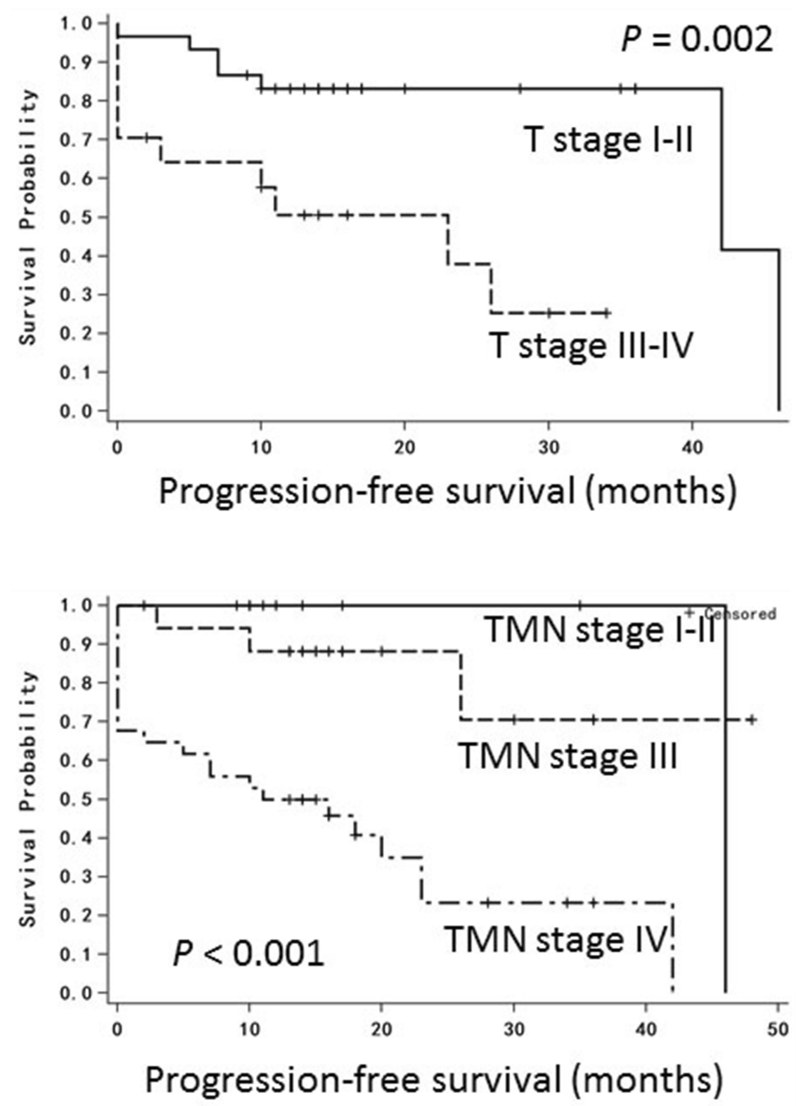

$(P=0.004)$, CA125 $(P=0.004)$ and CA153 $(P=0.045)$ (Figure 4). Of clinical importance, the PFS were also associated with the treatment strategy administered (surgical intervention, $P=0.025$; first-line chemotherapy, $P<0.001$ ) (Figure 5).

\section{Discussion}

The present study provided a comprehensive analysis on the clinical correlates of patients' outcomes after cancer treatment. Our analysis indicated the clear association between the number of CTCs and the OS of patients the larger the number of CTCs, the poorer the prognosis of patients after treatment. We also illustrated the correlation of patients' outcomes with tumor characteristics, levels of cancer biomarkers, and treatment strategy. Nearly half of our study subjects were cigarette smokers, and about twothirds of the entire study population had their tumors diagnosed as the advanced one. Our study resembles most clinical situations worldwide, in which cigarette smoking is the major etiology of lung cancers and diagnosed new cases are advanced tumors.

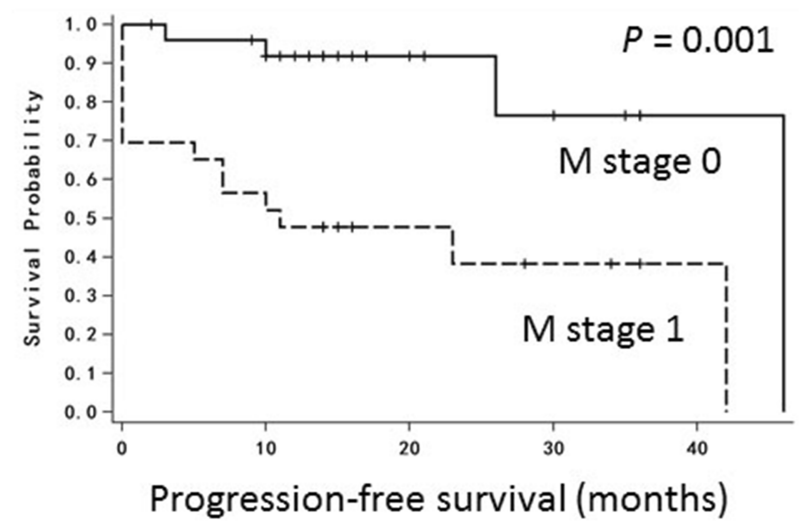

Figure 3 Kaplan-Meier curves showing the progression-free survivals of patients with different tumor backgrounds. $P$-value of the comparison was determined using log rank test. 

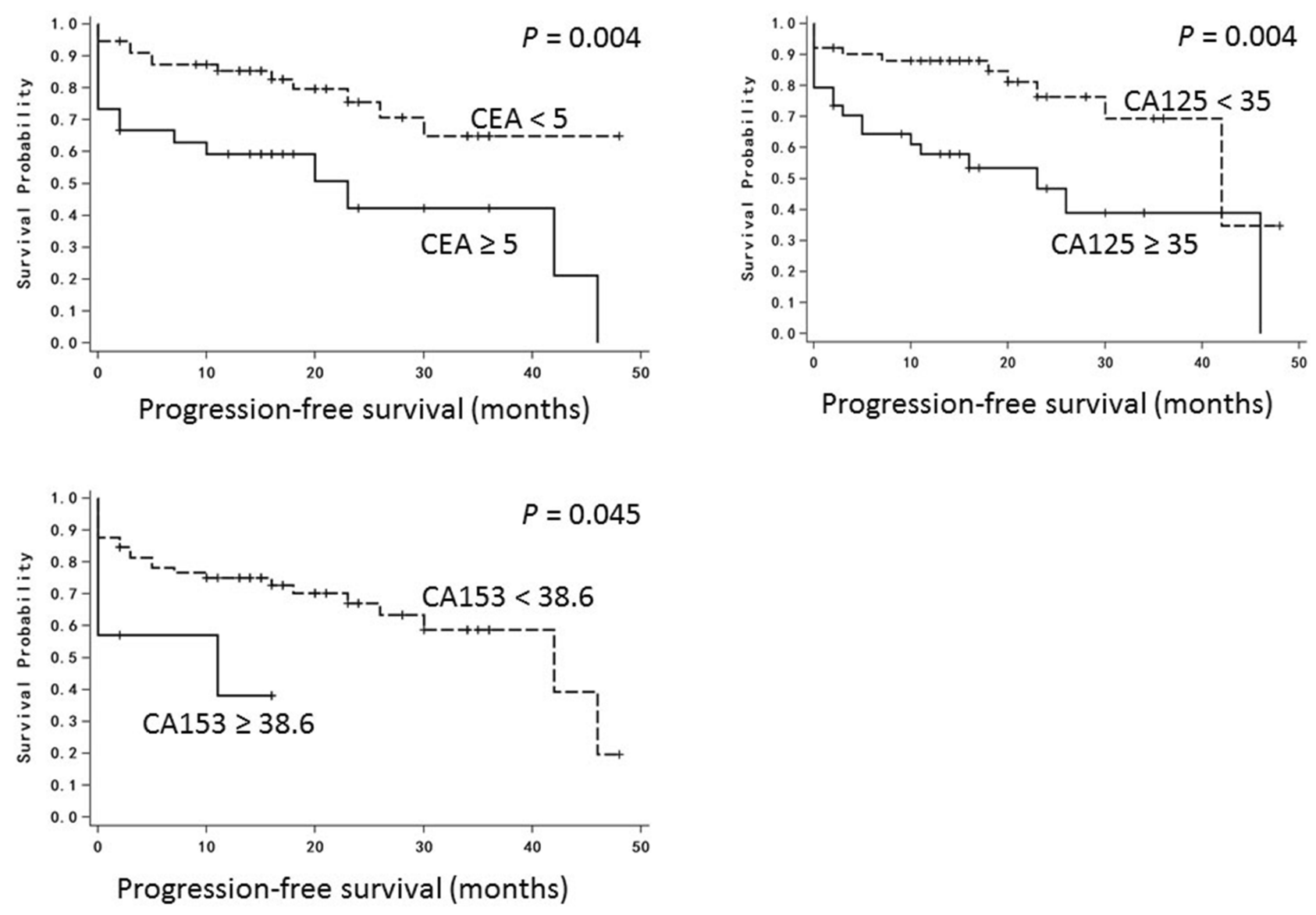

Figure 4 Kaplan-Meier curves showing the progression-free survivals of patients with different levels of cancer biomarkers. P-value of the comparison was determined using log rank test.
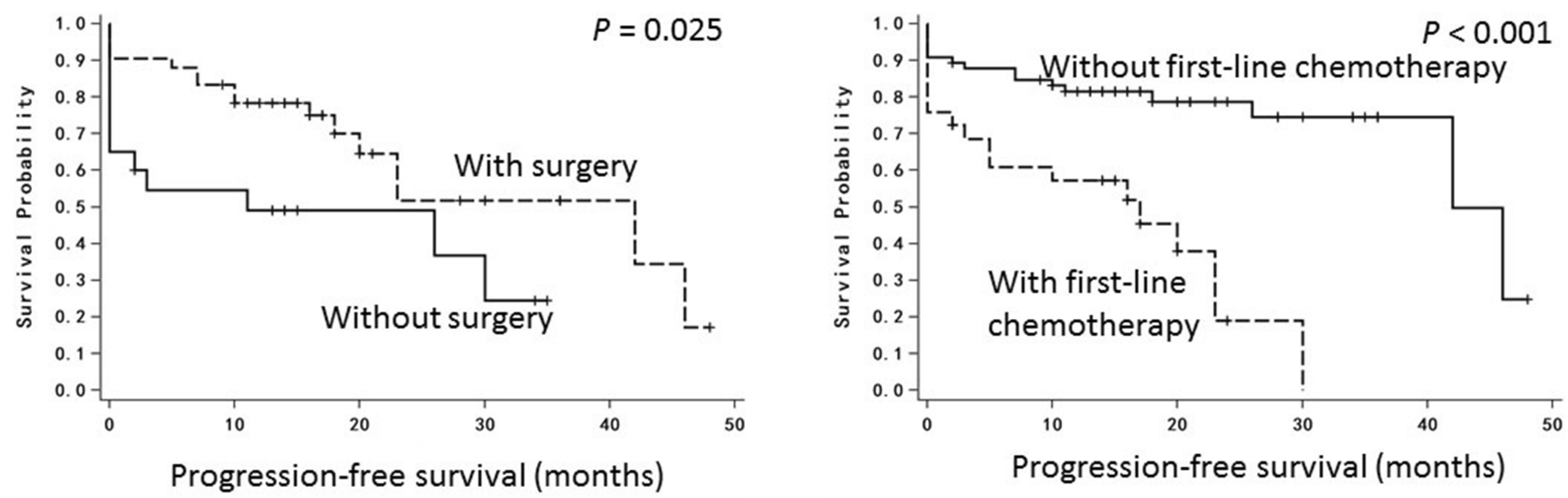

Figure 5 Kaplan-Meier curves showing the progression-free survivals of patients receiving different treatments (with and without surgery and with and without first-line chemotherapy). P-value of the comparison was determined using log rank test.

With the advent of new technologies, the enumeration of CTCs, of which the frequency is very low compared to bother blood cells, has become much more accurate, prompting studies into the prognostic relevance of CTC in patients with malignant diseases including lung cancers.
A prospective study in patients with previously untreated stage III or IV non-small cell lung carcinoma (NSCLC) showed that patients with small CTC count (ie, <5) presented a better progression-free survival (6.8 vs 2.4 months) and overall survival ( 8.1 vs 4.3 months) when 
compared with their counterparts with large CTC count (ie, $\geq 5) .{ }^{15}$ Another study in patients who underwent radical surgery for NSCLC demonstrated that the presence of CTCs after surgery was significantly associated with early recurrence and a shorter disease-free survival. ${ }^{16}$ In addition, a phase II clinical study of HER2-targeting pertuzumab plus erlotinib in relapsed NSCLC illustrated that higher baseline CTC counts were associated with the treatment response. ${ }^{17}$ In accordance to these important studies, our analysis revealed the close associations between CTC count and overall survival of Chinese patients. Our data would further strengthen the prognostic values of CTC in lung cancer. Chen et $\mathrm{al}^{18}$ reported in his study on 473 Chinese patients that the CTC levels were significantly elevated in patients with stage III/IV NSCLC compared with those with stage I/II NSCLC. The study also showed that CTC counts were associated with cancer biomarkers. The present study showed neither such CTC elevation in late stage NSCLC nor CTC correlation with cancer biomarkers. This discrepancy between the two studies might be due to the different methods of CTC enumeration and patient enrollment requirement.

The present study also underscored the effect of treatment strategy on the PFS of our patients. Our analysis showed that the use of adjuvant chemotherapy and surgery prolonged the OS and PFS, respectively. We have not analyzed the survival of patients treated with different chemotherapy because of the relatively small size of the patient population. Nevertheless, our results would shed light into the refinement of management strategy of patients with advanced lung cancers.

Our study, although comprehensive, has few limitations. Compared to many published similar studies, the sample size of the present study was relatively small. Since the present study is a retrospective one, the medical records of some patients have missed a few clinical parameters. Besides, the cohort of the present study is heterogeneous about the treatments. The present study has also not investigated the genetic aberrations within CTCs which would be associated with patients' prognosis. There are accumulated studies suggesting the genetic alterations identified from CTCs would be prognostic. ALK-gene rearrangement was associated with the mesenchymal phenotype of CTCs and in turn the metastatic potential of primary tumors. ${ }^{19}$ Indeed, accurate identification of specific genetic alternations can benefit the treatment of patients; for example, a clinical study showed that ALK TKI was effective against ALK-positive nonsmall-cell lung cancers. ${ }^{20}$ To summarize, the present study provides a comprehensive picture depicting the association of patients' survival with CTC counts in lung cancer, a deadly malignancy that affects populations worldwide.

\section{Disclosure}

The authors declare there is no conflict of interest in this study.

\section{References}

1. Torre LA, Siegel RL, Ward EM, Jemal A. Global cancer incidence and mortality rates and trends-an update. Cancer Epidemiol Biomark Prev. 2016;25(1):16-27. doi:10.1158/1055-9965.EPI-15-0578

2. Jemal A, Thun MJ, Ries LA, et al. Annual report to the nation on the status of cancer, 1975-2005, featuring trends in lung cancer, tobacco use, and tobacco control. J Natl Cancer Inst. 2008;100(23):16721694. doi:10.1093/jnci/djn389

3. Chalela R, Curull V, Enriquez C, Pijuan L, Bellosillo B, Gea J. Lung adenocarcinoma: from molecular basis to genome-guided therapy and immunotherapy. J Thorac Dis. 2017;9(7):2142-2158. doi:10.21037/ jtd.2017.06.20

4. Gibelin C, Couraud S. Somatic alterations in lung cancer: do environmental factors matter? Lung Cancer. 2016;100:45-52. doi:10.1016/j. lungcan.2016.07.015

5. Ruano-Ravina A, Fernandez-Villar A, Barros-Dios JM. Residential radon and risk of lung cancer in never-smokers. Arch Bronconeumol. 2017;53(9):475-476. doi:10.1016/j.arbres.2017.01.004

6. Datta D, Lahiri B. Preoperative evaluation of patients undergoing lung resection surgery. Chest. 2003;123(6):2096-2103. doi:10.1378/ chest.123.6.2096

7. Schiller JH, Harrington D, Belani CP, et al. Comparison of four chemotherapy regimens for advanced non-small-cell lung cancer. $N$ Engl J Med. 2002;346(2):92-98. doi:10.1056/NEJMoa011954

8. Allard WJ, Matera J, Miller MC, et al. Tumor cells circulate in the peripheral blood of all major carcinomas but not in healthy subjects or patients with nonmalignant diseases. Clin Cancer Res. 2004;10 (20):6897-6904. doi:10.1158/1078-0432.CCR-04-0378

9. Hodgkinson CL, Morrow CJ, Li Y, et al. Tumorigenicity and genetic profiling of circulating tumor cells in small-cell lung cancer. Nat Med. 2014;20(8):897-903. doi:10.1038/nm.3600

10. Cristofanilli M, Budd GT, Ellis MJ, et al. Circulating tumor cells, disease progression, and survival in metastatic breast cancer. $N$ Engl $J$ Med. 2004;351(8):781-791. doi:10.1056/NEJMoa040766

11. Messaritakis I, Sfakianaki M, Papadaki C, et al. Prognostic significance of CEACAM5mRNA-positive circulating tumor cells in patients with metastatic colorectal cancer. Cancer Chemother Pharmacol. 2018;82(5):767-775. doi:10.1007/s00280-018-3666-9

12. de Bono JS, Scher HI, Montgomery RB, et al. Circulating tumor cells predict survival benefit from treatment in metastatic castration-resistant prostate cancer. Clin Cancer Res. 2008;14(19):6302-6309. doi:10.1158/1078-0432.CCR-08-0872

13. Tognela A, Spring KJ, Becker T, et al. Predictive and prognostic value of circulating tumor cell detection in lung cancer: a clinician's perspective. Crit Rev Oncol Hematol. 2015;93(2):90-102. doi:10.1016/j. critrevonc.2014.10.001

14. Alama A, Truini A, Coco S, Genova C, Grossi F. Prognostic and predictive relevance of circulating tumor cells in patients with nonsmall-cell lung cancer. Drug Discov Today. 2014;19(10):1671-1676. doi:10.1016/j.drudis.2014.06.001

15. Krebs MG, Sloane R, Priest L, et al. Evaluation and prognostic significance of circulating tumor cells in patients with non-small-cell lung cancer. J Clin Oncol. 2011;29(12):1556-1563. doi:10.1200/JCO.2010.28.7045 
16. Bayarri-Lara C, Ortega FG, Cueto Ladron de Guevara A, et al. Circulating tumor cells identify early recurrence in patients with non-small cell lung cancer undergoing radical resection. PLoS One. 2016;11(2):e0148659. doi:10.1371/journal.pone.0148659

17. Punnoose EA, Atwal S, Liu W, et al. Evaluation of circulating tumor cells and circulating tumor DNA in non-small cell lung cancer: association with clinical endpoints in a phase II clinical trial of pertuzumab and erlotinib. Clin Cancer Res. 2012;18(8):2391-2401. doi:10.1158/1078-0432.CCR-11-3148

18. Chen X, Zhou F, Li X, et al. Folate receptor-positive circulating tumor cell detected by LT-PCR-based method as a diagnostic biomarker for non-small-cell lung cancer. J Thorac Oncol. 2015;10 (8):1163-1171. doi:10.1097/JTO.0000000000000606
19. Pailler E, Adam J, Barthelemy A, et al. Detection of circulating tumor cells harboring a unique ALK rearrangement in ALK-positive non-small-cell lung cancer. J Clin Oncol. 2013;31(18):2273-2281. doi:10.1200/JCO.2012.44.5932

20. Kwak EL, Bang YJ, Camidge DR, et al. Anaplastic lymphoma kinase inhibition in non-small-cell lung cancer. $N$ Engl J Med. 2010;363 (18):1693-1703. doi:10.1056/NEJMoa1006448

\section{Publish your work in this journal}

OncoTargets and Therapy is an international, peer-reviewed, open access journal focusing on the pathological basis of all cancers, potential targets for therapy and treatment protocols employed to improve the management of cancer patients. The journal also focuses on the impact of management programs and new therapeutic

Submit your manuscript here: https://www.dovepress.com/oncotargets-and-therapy-journal agents and protocols on patient perspectives such as quality of life, adherence and satisfaction. The manuscript management system is completely online and includes a very quick and fair peer-review system, which is all easy to use. Visit http://www.dovepress.com/ testimonials.php to read real quotes from published authors. 